\title{
KIR AND HLA HAPLOTYPE ANALYSIS IN A FAMILY LACKING THE KIR 2DL1-2DP1 GENES
}

\author{
Vojvodić S*, Ademović-Sazdanić D
}

\begin{abstract}
*Corresponding Author: Associate Professor Svetlana Vojvodić, Institute for Blood Transfusion of Vojvodina, Tissue Typing Compartment, Medical Faculty of the University of Novi Sad, Hajduk Veljkova 9a, 21000 Novi Sad, Serbia; Tel: +381-21-4877-963, Fax: +381-21-4877-978; E-mail: svetlana.vojvodic021@gmail.com
\end{abstract}

\begin{abstract}
The killer cell immunoglobulin-like receptor $(K I R)$ gene cluster exhibits extensive allelic and haplotypic diversity that is observed as presence/absence of genes, resulting in expansion and contraction of KIR haplotypes and by allelic variation of individual $K I R$ genes. We report a case of KIR pseudogene $2 D P I$ and $2 D L 1$ gene absence in members of one family with the children suffering from acute myelogenous leukemia (AML). Killer cell immunoglo-bulin-like receptor low resolution genotyping was performed by the polymerase chain reaction (PCR)-sequencespecific primers (SSP)/sequence-specific oligonucleotide (SSO) method and haplotype assignment was done by gene content analysis. Both parents and the maternal grandfather, shared the same Cen-B2 KIR haplotype, containing KIR $3 D L 3,-2 D S 2,-2 D L 2$ and $-3 D P 1$ genes. The second haplotype in the KIR genotype of the mother and grandfather was Tel-A1 with KIR 2DL4 (normal and deleted variant), $-3 D L 1,-22$ bp deletion variant of the $2 D S 4$ gene and $-3 D L 2$, while the second haplotype in the KIR genotype of the father was Tel-B1 with $2 D L 4$ (normal variant), $-3 D S 1,-2 D L 5,-2 D S 5,-2 D S 1$ and $3 D L 2$ genes. Haplotype analysis in all three offsprings revealed that the children inherited the Cen-B2 haplotype with the same gene content but two of the children inherited a deleted variant of the $2 D L 4$ gene, while the third
\end{abstract}

\footnotetext{
Tissue Typing Compartment, Institute for Blood Transfusion of Vojvodina, Novi Sad, Serbia
}

child inherited a normal one. The second haplotype of all three offspring contained KIR $2 D L 4,-2 D L 5$, $-2 D S 1,-2 D S 4$ (del 22bp variant), $-2 D S 5,-3 D L 1$ and $-3 D L 2$ genes, which was the basis of the assumption that there is a hybrid haplotype and that the present $3 D L 1$ gene is a variant of the $3 D S 1$ gene. Due to consanguinity among the ancestors, the results of KIR segregation analysis showed the existence of a very rare KIR genotype in the offspring. The family who is the subject of this case is even more interesting because the father was 10/10 human leukocyte antigen (HLA)-matched to his daughter, all members of the family have the "best" donor KIR-B content and the presence of a rare KIR genotype with KIR 2DP1-2DL1 genes absence.

Keywords: Human leukocyte antigen (HLA) and killer cell immunoglobin-like receptor (KIR) polymorphism; natural killer (NK) cells

\section{INTRODUCTION}

Natural killer (NK) cells of innate immunity and $\mathrm{CD} 8^{+}$cytotoxic $\mathrm{T}$ cells (CTL) of adaptive immunity are professional killer cells that are necessary for defense against virus-infected or tumor-transformed cells. Natural killer cells recognize and kill target cells with absent or altered expression of human leukocyte antigen (HLA) class I molecules. This missing self recognition makes NK cells able to eliminate tumoral and virus-infected cells that lack self HLA class I molecules. Furthermore, in the allogeneic context of hematopoietic stem cell transplantation, 
NK cells from the donor can be alloreactive against recipient cells. This NK cell alloreactivity is mediated by a balance between activating and inhibitory signals and leads to cytotoxicity and production of proinflammatory cytokines, such as IFN- $\gamma$. Receptors of HLA class I molecules involved in recognition of target cells partly belong to the killer cell Ig-like receptor (KIR) family, encoded by 14 genes and two pseudogenes located on chromosome 19q13.4, within a 100 to $200 \mathrm{~kb}$ region of the leukocyte receptor complex (LRC) [1-5]. The number of genes present in KIR haplotypes is variable, however four genes (KIR 3DL3, KIR3DP1, KIR2DL4, KIR3DL2) are present on virtually all haplotypes, and are thus considered as framework genes. Two major classes of KIR haplotypes (A and B) have been identified, which is unique to the human species and that were shown to have differential associations with disease and reproductive success. The A haplotype contains four genes in addition to the framework genes (KIR2DL1, KIR2DL3, KIR3DL1, KIR2DS4), representing a predominantly inhibitory haplotype. There are many B haplotypes, containing various combinations of the activating KIR genes [1-3,6-9]. In addition to the substantial variation in gene content across haplotypes, each KIR gene itself exhibits considerable nucleotide sequence polymorphism explaining why the genomic diversity of the human $K I R$ gene family is its important characteristic attributed to the variability in both gene numbers and allelic polymorphism [7,9-11]. Every KIR haplotype is a combination of a centromeric and a telomeric KIR gene motif. DNA sequencing of single copies of chromosome $19[8,12]$ and family segregation analysis $[13,14]$ have defined three common centromeric (Cen-A1, Cen-B1, Cen-B2) and two common telomeric (Tel-A1 and Tel-B1) haplotype structures based on the presence and absence of specific $K I R$ genes. As examples, Cen-A1 is comprised of KIR $3 D L 3 \sim K I R 2 D L 3 \sim K I R 2 D P 1 \sim K I R 2 D L 1 \sim K I R$ $3 D P 1$ in this gene order, whereas Tel-A1 includes KIR2DL4 KIR3DL1 KIR2DS4 KIR3DL2. In this report, we present a detailed HLA and KIR haplotype analysis of a family having rare KIR genotype. All members of the family described here displayed a greater degree of diversity of KIR genetic profiles, that indicates further complexity of underlying haplotypes; in this respect, we described six individuals (grandfather, mother, father and three offspring), who possess an incomplete KIR haplotype with the $3 D P 1$ variant allele (due to lack of $2 D P 1-2 D L 1$ alleles). The aim of the presented case study was to determine possible explanation of rare KIR genotype present in patient, siblings and parents of the patient, through the segregation KIR analysis in patient's grandfather and grandmothers.

\section{MATERIAL AND METHODS}

Patient History. An 8-year old female patient (M.M.), suffering from acute myelogenous leukemia (AML), her parents [father (M.A.) 37 years old, mother (M.Z.) 32 years old], two siblings (M.M. and M.Z.), aged 14 and 10, maternal grandparents: grandfather (M.M., 67 years old), grandmother (M.M., 56 years old), and paternal grandmother: (M.T., 63 years old), were reported. The paternal grandfather (M.F.), who passed away 2 years ago, was not included in the case study, therefore, we were unable to show both his KIR and HLA genotypes, but only the one inherited by his son, the patient's father (M.A.).

Family History. There were no known disorders from which direct blood relatives of the patient suffered, with the exception of hypertension, which both of the patient's grandmothers suffer. There are the data on consanguinity among family members: great-grandmother of the patient's father (M.A.) and grandfather of the patient's mother (M.Z.), were siblings. Therefore, the mother and the father of the patient are third-degree cousins.

DNA Extraction and Human Leukocyte Antigen Genotyping. DNA extraction was performed by a silica-based extraction method, using the QIAamp DNA Mini Kit (Qiagen GmbH, Hilden, Germany) or the GeneJET Genomic DNA Purification Kit (Thermo Fisher Scientific Inc., Vilnius, Lithuania) from $200 \mu \mathrm{L}$ of buffy-coat obtained from $3 \mathrm{~mL}$ of blood collected in EDTAcontaining vacutainers. The DNA was rehydrated with pure water and the DNA concentration and purity was determined by Eppendorf BioPhotometer (Eppendorf AG, Hamburg, Germany). The HLA and KIR genotyping was performed by a reverse sequence-specific oligonucleotide (SSO) probe method coupled with the multiplexed microspherebased suspension array platform xMAP technology designed for use with the Luminex ${ }^{\circledR}$ system to identify HLA and KIR alleles encoded by sample 
DNA using Lifecodes KIR/HLA SSO Typing kits, Gen-Probe Transplant Diagnostics, Inc. (Stamford, CT, USA). The target DNA was first amplified by polymerase chain reaction (PCR) with biotinylated primers specifically designed for each HLA and KIR locus. The PCR product was denatured and hybridized to complementary oligonucleotide probes immobilized on fluorescently coded microsphere beads. At the same time, the biotinylated PCR product was labeled with phycoerythrin-conjugated streptavidin to allow it to be detected by the Luminex ${ }^{\circledR}$ system. The HLA and KIR alleles were assigned by analysis of the reaction (hybridization) pattern of the target sample using the Quicktype for Lifecodes software. Verification of HLA and KIR genotyping was based on a PCR-SSP (sequence-specific primers) technique using HLA-Ready Gene and KIR-Ready Gene kits (Inno-Train Diagnostik GmbH, Kronberg, Germany). The cycling program involved the initial denaturation at $96{ }^{\circ} \mathrm{C}$ for $2 \mathrm{~min}$. followed by 10 cycles of denaturation at $96^{\circ} \mathrm{C}$ for 15 seconds, annealing at $65^{\circ} \mathrm{C}$ for 60 seconds, and followed by 20 cycles of denaturation at $96^{\circ} \mathrm{C}$ for 15 seconds, annealing at $61{ }^{\circ} \mathrm{C}$ for 50 seconds, and elongation at $72{ }^{\circ} \mathrm{C}$ for 30 seconds. Electrophoresis using $2.0 \%$ agarose gel was done. After PCR, created bands in each well were interpreted based on standard protocol available in the kit, using Helmberg SCORETM software. The genotype of each individual was typed specifically.

\section{RESULTS}

The distribution of KIR and HLA genes of the patient's grandparents (two grandmothers and one available grandfather), is presented in Table 1. The KIR segregation analysis showed that grandfather of the patient (M.M.), appears to be homozygous for the Cen-B2/Tel-A1 KIR haplotype, and that he shares the same KIR haplotype with his wife [grandmother of the patient (M.M)] with only difference in KIR 2DL4 gene [normal KIR 2DL4 gene variant present in grandfather and deleted KIR 2DL4 gene variant present in grandmother (M.M.)]. The HLA segregation analyses point out that the maternal grandfather (M.M.) and paternal grandmother (M.T.) share the same HLA haplotype: $A^{*} 32 \sim B * 27 \sim C^{*} 02 \sim D R B 1 * 16 \sim D Q B 1 * 05$ (Table 1).

The distribution of KIR and HLA genes of the parents in the family that is under study is given in Table 2. The HLA and KIR haplotype analysis revealed that both parents were lacking the KIR2DP1$2 D L 1$ genes and that they were mutually compatible in eight out of 10 HLA alleles.

Table 3 shows the distribution of KIR and HLA alleles in the offspring, where it is noticeable that all three offspring also lacked the $2 D P 1-2 D L 1$ genes and that the brothers were mutually 10/10 HLAmatched and both were HLA haploidentical to the patient. Additionally, the patient carries the $\mathrm{C} 1 / \mathrm{C} 2$ HLA genotype, as she possess $\mathrm{C}^{*} 07$ belonging to

Table 1. Distribution of KIR and HLA alleles in the paternal and maternal grandparents.

\begin{tabular}{|c|c|c|c|c|c|c|c|}
\hline \multicolumn{4}{|c|}{ Paternal Grandparents } & \multicolumn{4}{|c|}{ Maternal Grandparents } \\
\hline \multicolumn{2}{|c|}{ Grandmother (M.T.) } & \multicolumn{2}{|c|}{ Grandfather (M.F.) } & \multicolumn{2}{|c|}{ Grandmother (M.M.) } & \multicolumn{2}{|c|}{ Grandfather (M.M.) } \\
\hline KIR & HLA & KIR & HLA & KIR & HLA & KIR & HLA \\
\hline $\begin{array}{l}\text { Cen-B2/Tel-B1 } \\
\& \\
\text { Cen-A1/Tel-A1 }\end{array}$ & & $\begin{array}{l}\text { Cen-B2/Tel-B1 } \\
\text { (second unknown) }\end{array}$ & $\begin{array}{l}\text { (second } \\
\text { unknown) }\end{array}$ & $\begin{array}{l}\text { Cen-B1/Tel-A1 } \\
\& \\
\text { Cen-B2/Tel-A1 }\end{array}$ & & $\begin{array}{l}\text { Cen-B2/Tel-A1 } \\
\& \\
\text { Cen-B2/Tel-A1 }\end{array}$ & \\
\hline $\begin{array}{l}3 D L 3 \\
2 D S 2 \\
2 D L 2 \\
3 D P 1 \\
2 D L 4 \text { (normal } \\
\text { and deleted) } \\
3 D S 1 \\
2 D L 5 \\
2 D S 5 \\
2 D S 1 \\
3 D L 2\end{array}$ & $\begin{array}{l}\text { A*11, *32 } \\
\text { B*27, *58 } \\
\text { C*02, *07 } \\
\text { DRB1*07, *16 } \\
\text { DQB1*03, *05 }\end{array}$ & $\begin{array}{l}3 D L 3 \\
2 D S 2 \\
2 S L 2 \\
3 D P 1 \\
2 D L 4 \text { (normal) } \\
3 D S 1 \\
2 D L 5 \text { (null } B * 004) \\
2 D S 5 \\
2 D S 1 \\
3 D L 2\end{array}$ & $\begin{array}{l}A * 02 \\
B * 41 \\
C * 07 \\
D R B 1 * 03 \\
\text { DQB1*02 }\end{array}$ & \begin{tabular}{|l}
$3 D L 3$ \\
$2 D S 2$ \\
$2 D L 2$ \\
$2 D L 5 \mathrm{Xa}, X b$ \\
$2 D S 3$ \\
$2 D P 1$ \\
$2 D L 1$ \\
$3 D P 1$ \\
$2 D L 4$ (deleted) \\
$3 D L 1$ \\
$2 D S 4$ (del $22 \mathrm{bp}$ ) \\
$3 D L 2$
\end{tabular} & \begin{tabular}{|l}
$\mathrm{A} * 02, * 24$ \\
$\mathrm{~B} * 08, * 41$ \\
$\mathrm{C} * 07, * 07$ \\
$\mathrm{DRB} 1 * 03, * 03$ \\
$\mathrm{DQB} 1 * 02, * 02$ \\
\end{tabular} & \begin{tabular}{|l|}
$3 D L 3$ \\
$2 D S 2$ \\
$2 D L 2$ \\
$3 D P 1$ \\
$2 D L 4$ (normal \\
and deleted) \\
$3 D L 1$ \\
$2 D S 4$ (del $22 \mathrm{bp}$ ) \\
$3 D L 2$
\end{tabular} & \begin{tabular}{|l} 
A*24,*32 \\
B*27,*44 \\
C*02,*02 \\
DRB1*14, ${ }^{*} 16$ \\
DQB1 ${ }^{*} 05, * 05$
\end{tabular} \\
\hline
\end{tabular}


Table 2. Distribution of KIR and HLA alleles in the parents.

\begin{tabular}{|c|c|c|c|}
\hline \multicolumn{2}{|l|}{ Mother (M.Z.) } & \multicolumn{2}{|l|}{ Father (M.A.) } \\
\hline KIR & HLA & KIR & HLA \\
\hline $\begin{array}{l}\text { Cen-B2/Tel-A1 \& } \\
\text { Cen-B2/Tel-A1 }\end{array}$ & & $\begin{array}{l}\text { Cen-B2/Tel-B1 \& } \\
\text { Cen-B2/Tel-B1 }\end{array}$ & \\
\hline $\begin{array}{l}3 D L 3 \\
2 D S 2 \\
2 D L 2 \\
3 D P 1 \\
2 D L 4 \text { (normal and deleted) } \\
3 D L 1 \\
2 D S 4 \text { (del } 22 b p) \\
3 D L 2\end{array}$ & $\begin{array}{l}\mathrm{A} * 24, * 32 \\
\mathrm{~B} * 08, * 27 \\
\mathrm{C} * 02, * 07 \\
\mathrm{DRB} 1 * 03, * 16 \\
\mathrm{DQB} 1 * 02, * 05\end{array}$ & $\begin{array}{l}3 D L 3 \\
2 D S 2 \\
2 D L 2 \\
3 D P 1 \\
2 D L 4 \text { (normal) } \\
3 D S 1 \\
2 D L 5(A * 001 \& \text { null } B * 004) \\
2 D S 5 \\
2 D S 1 \\
3 D L 2\end{array}$ & $\begin{array}{l}\mathrm{A} * 02, * 32 \\
\mathrm{~B} * 27, * 41 \\
\mathrm{C} * 02, * 07 \\
\text { DRB1*03, *16 } \\
\text { DQB1*02, *05 }\end{array}$ \\
\hline
\end{tabular}

Table 3. Distribution of KIR and HLA alleles in the offspring.

\begin{tabular}{|c|c|c|c|c|c|}
\hline \multicolumn{2}{|l|}{ Patient (M.M.) } & \multicolumn{2}{|l|}{ Brother(M.M.) } & \multicolumn{2}{|l|}{ Brother(M.Z.) } \\
\hline KIR & HLA & KIR & HLA & KIR & HLA \\
\hline $\begin{array}{l}\text { Cen-B2/Tel-A1 \& } \\
\text { Cen-B2/Tel-B1 }\end{array}$ & & $\begin{array}{l}\text { Cen-B2/Tel-A1 \& } \\
\text { Cen-B2/Tel-B1 }\end{array}$ & & $\begin{array}{l}\text { Cen-B2/Tel-A1 \& } \\
\text { Cen-B2/Tel-B1 }\end{array}$ & \\
\hline $\begin{array}{l}3 D L 3 \\
2 D S 2 \\
2 D L 2 \\
3 D P 1 \\
2 D L 4 \text { (deleted) } \\
3 D L 1 \\
2 D S 4 \text { (del 22bp) } \\
2 D L 5 \text { (null } B * 004) \\
2 D S 5 \\
2 D S 1 \\
3 D L 2\end{array}$ & $\begin{array}{l}\mathrm{A} * 02, * 32 \\
\mathrm{~B} * 27, * 41 \\
\mathrm{C} * 02, * 07 \\
\mathrm{DRB} 1 * 03, * 16 \\
\mathrm{DQB} 1 * 02, * 05\end{array}$ & $\begin{array}{l}3 D L 3 \\
2 D S 2 \\
2 D L 2 \\
3 D P 1 \\
2 D L 4 \text { (normal) } \\
3 D L 1 \\
\left.2 D L 5 \text { (null } B^{*} 004\right) \\
2 D S 5 \\
2 D S 1 \\
2 D S 4 \text { (del } 22 \mathrm{bp}) \\
3 D L 2\end{array}$ & $\begin{array}{l}\mathrm{A} * 02, * 24 \\
\mathrm{~B} * 08, * 41 \\
\mathrm{C} * 07, * 07 \\
\mathrm{DRB} 1 * 03, * 03 \\
\mathrm{DQB} 1 * 02, * 02\end{array}$ & $\begin{array}{l}3 D L 3 \\
2 D S 2 \\
2 D L 2 \\
3 D P 1 \\
2 D L 4 \text { (deleted) } \\
3 D L 1 \\
\left.2 D L 5 \text { (null } B^{*} 004\right) \\
2 D S 5 \\
2 D S 1 \\
2 D S 4 \text { (del } 22 \mathrm{bp}) \\
3 D L 2\end{array}$ & $\begin{array}{l}\mathrm{A} * 02, * 24 \\
\mathrm{~B} * 08, * 41 \\
\mathrm{C} * 07, * 07 \\
\mathrm{DRB} 1 * 03, * 03 \\
\mathrm{DQB} 1 * 02, * 02\end{array}$ \\
\hline
\end{tabular}

the $\mathrm{C} 1$ group and $\mathrm{C}^{*} 02$, belonging to the $\mathrm{C} 2$ group. Also there is one KIR/HLA mismatch between the siblings and both the parents toward the patient for KIR 3DL2 gene, since patient lacks the HLA A*03 and A*11 ligands. Father is 10/10 HLA-matched to the daughter (at a low resolution typing level), while her mother is 8/10 HLA-matched donor.

The analysis of familial HLA haplotypes segregation presented in Figure 1 revealed that all three children inherited the same haplotype from the father $\left(A^{*} 02 \sim B^{*} 41 \sim C^{*} 07 \sim D R B 1 * 03 \sim D Q B 1 * 02\right)$, two brothers inherited the same HLA haplotype from the mother $(A * 24 \sim B * 08 \sim C * 07 \sim D R B 1 * 03 \sim D Q B 1 * 02)$ and the patient inherited the the mother's second hap- lotype $(A * 32 \sim B * 27 \sim C * 02 \sim D R B 1 * 16 \sim D Q B 1 * 05)$, which explains why the brothers were mutually $10 / 10$ HLA-matched and haploidentical compared to the patient.

Figure 2 provides the KIR haplotype analysis showing that all members of the family predominantly possess Cen-B2 motifs in combination with Tel-A1 and Tel-B1, respectively, with the exception of the Cen-A1 motif, present in the paternal grandmother (M.T.). The maternal grandfather (M.M.), parents and offspring in the family carry incomplete KIR haplotypes with the $3 D P 1$ variant allele (due to lack of $2 D P 1-2 D L 1$ alleles) and that the maternal grandfather, mother and the father are homozygous for the Cen-B2 haplo- 


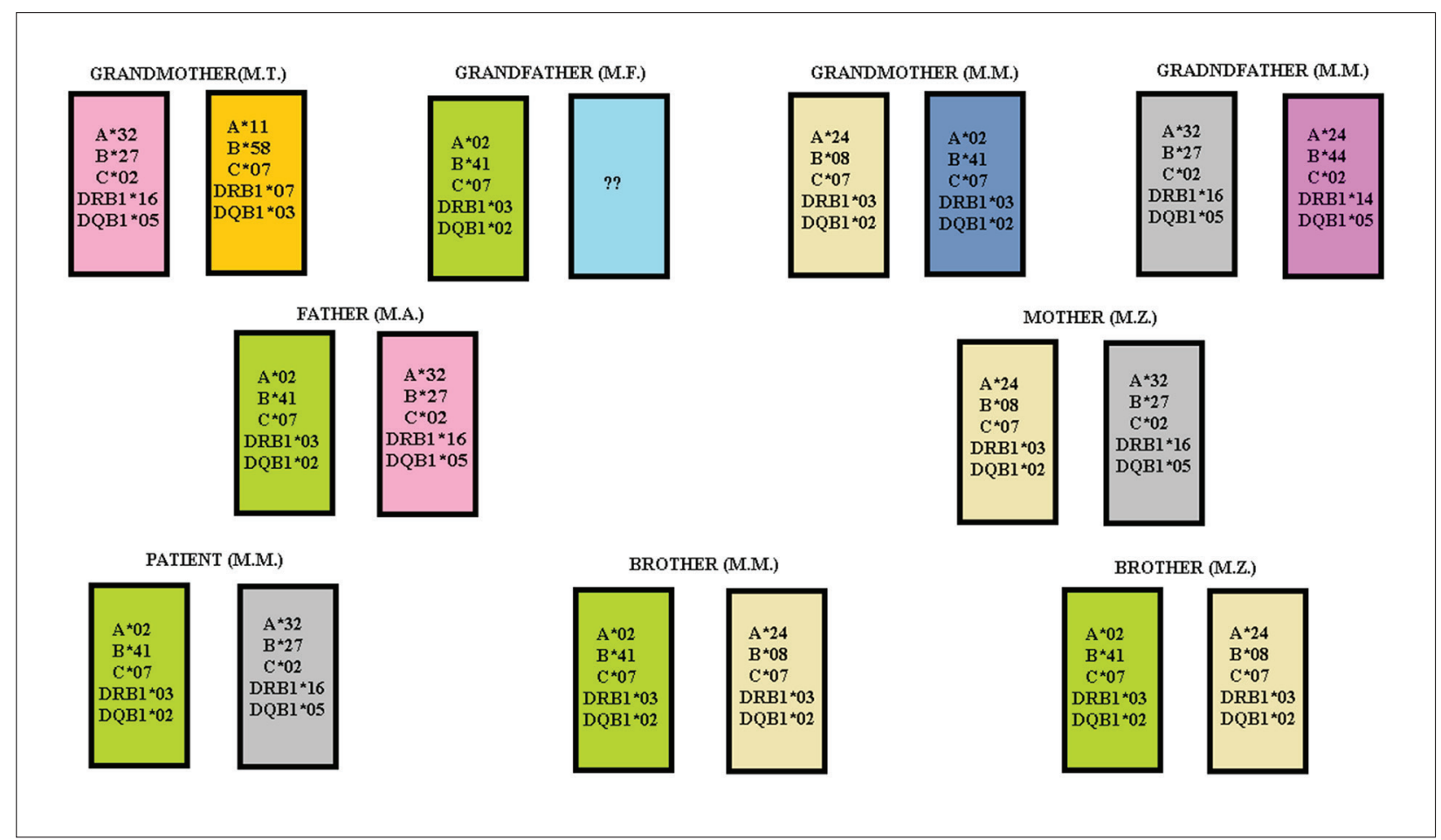

Figure 1. Analysis of the $H L A$ gene segregation revealed that the maternal grandfather (M.M.) And paternal grandmother (M.T.) shared the same HLA haplotype: $A * 32 \sim B * 27 \sim C * 02 \sim D R B 1 * 16 \sim D Q B 1 * 05$, resulting in their transfer to the mother, father and patient as well as to her siblings.

type containing following KIR genes: $3 D L 3 \sim 2 D S 2 \sim$ 2DL2 3DP1. Also all three offspring inherited the Cen-B2 haplotype with the same gene content but two of the children inherited a deleted variant of the 2DL4 gene, while the third child inherited the normal one. All three offspring inherited the deleted variant of the 2DS4 gene from their mother and they are homozygous for the Cen-B2 haplotype and heterozygous for the Tel-A1/Tel-B1 haplotypes. At the basis of the $K I R$ gene content present in the offspring, we assumed that there is a diversive/hybrid haplotype compared to the father's KIR haplotype (Tel-B1 containing KIR 3DP1 2DL4 3DS1 2DL5 2DS1 3DL2), since the $3 D S 1$ gene present in the offsprings' KIR haplotype (KIR 3DP1 2DL4 3DL1 2DL5 2DS1 3DL2), segregated as a $3 D L 1$ gene.

\section{DISCUSSION}

The KIR gene content and alleles vary across individual genomes and populations. The KIR genes are variable in gene content and type, which results in different KIR haplotypes, therefore, they can be used to discriminate individuals and populations from different regions or ethnic groups $[8,10,13]$. Several studies have verified the KIR diversity in different populations [15-24] and analyzed the genetic relationships among populations from different geographical areas and answered questions regarding ethnic origins [25-27]. The KIR diversity is observed as presence/absence of genes, resulting in expansion and contraction of KIR haplotypes [21,28,29], and further diversity is provided by allelic variation of individual KIR genes.

Our results indicate that KIR genotype frequencies described in the parents and offspring of the family have a specific structure: father (M.A.) has Cen-B2/Cen-B2 and Tel-B1/Tel-B1 genotype, mother (M.Z.) has Cen-B2/Cen-B2 and Tel-A1/Tel-A1 and the offspring all have Cen-B2/Cen-B2 and Tel-A1/ Tel-B1 genotypes. All healthy members of the family have the "best" B KIR gene content, including the grandmothers and grandfather of the patient [30]. The KIR genotypes existing in the maternal grandfather, parents and the offspring of described familiy are rare, as there are very low frequencies of these KIR 


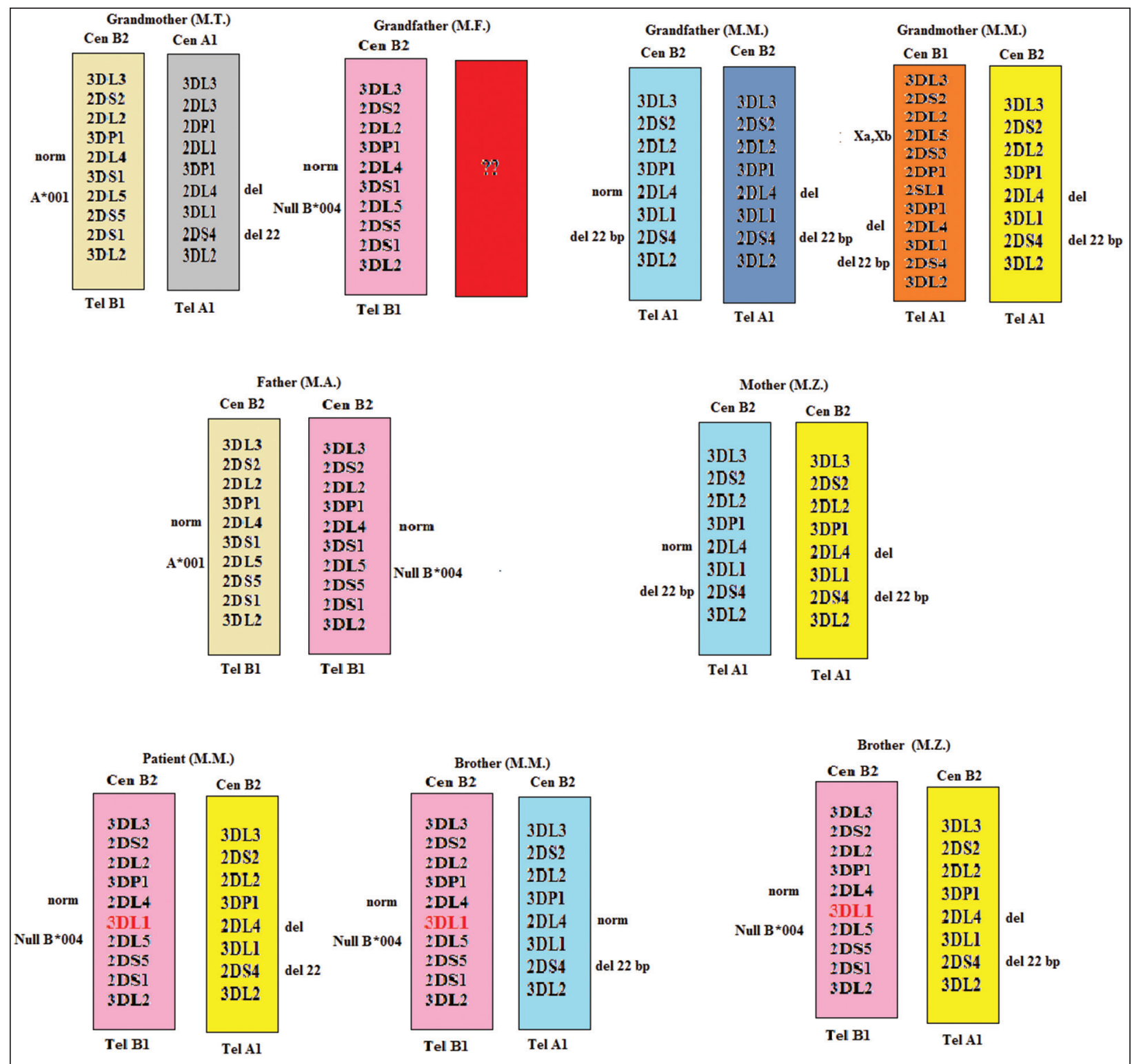

Figure 2. Analysis of the KIR gene segregation revealed that most members of the studied family carry incomplete KIR haplotypes with the $3 D P 1$ variant allele due to the lack of $2 D P 1-2 D L 1$ alleles with the exception of the paternal grandmother (M.T.).

genotypes in several Caucasoid populations. Among their KIR genotypes, the grandfather's and mother's genotype (Cen-B2/Tel-A1) is the most frequent (around 6.0\% Caucasoids possess it), father's genotype (Cen-B2/Tel-B1) is present in $2.9 \%$ Caucasoids, while the genotypes present in the offspring (Cen-B2/ Tel-B1 and Cen-B2/Tel-A1) is very rare, up to 1.0\% of Caucasoids possess these rare genotypes. Similar to the previous observation, absence of the $2 D P 1$ and $2 D L 1$ KIR genes is very rare, as the frequencies of these genes range from $87.0 \%$ in Belgium to $100.0 \%$ in Finland for $2 D L 1$ and from $89.0 \%$ in Portugal to $99.0 \%$ in Belgium for $2 D P 1$ [31]. Additionally, the KIR gene segregation analysis is interesting in the studied family as all three children should have the $3 D S 1$ gene from the father's haplotype (Tel-B1 part), but due to occurrence of some of the possible mechanisms: gene duplication, hybridization by assymetrical recombination or intergenic/ interlineage recombination during meiosis, we assumed that the present $3 D L 1$ gene is a variant of the $3 D S 1$ gene and $3 D S 1$ allele segregated as $3 D L 1$. As Norman et al. 
$[32,33]$ described, the explanation for the existence of $3 D L 1 * 009$, present in the offspring (according to the results of verification PCR-SSP genotyping), is that this allele is formed by conversion between $3 D L 1 * 001$ and $3 D S 1 * 01301$, resulting in a new haplotype with the $3 D L 1$ gene instead of $3 D S 1$. This is the proof that these genes behave as two alleles of the same gene. The possible explanation of the existence of such rare KIR genotypes in grandfather, parents and offspring in the family is consanguinity among their ancestors, which resulted in predominance of the Cen-B2 KIR haplotype in the family, homo-zygosity of Cen-B2/Tel-A1, present in grandfather (M.M.) and mother (M.Z.), homozygosity of Cen-B2/Tel-B1 present in father (M.A.), presence of the same HLA haplotype, $A^{*} 32 \sim B^{*} 27 \sim C^{*} 02 \sim D R B 1 * 16 \sim D Q B 1 * 05$, in the maternal grandfather (M.M.), paternal grandmother (M.T.), mother (M.Z.), father (M.A.) and the patient (M.M.).

The KIR and HLA segregation analysis of the studied family members was interesting for a several reasons: 1) presence of rare a KIR genotype with KIR 2DP1-2DL1 absence in grandfather and both parents and one Cen-B2 mutually shared haplotype; 2) presence of one diversive KIR haplotype in the offspring and also rare KIR genotype with absence of KIR 2DP1-2DL1 genes; 3 ) there is the existence of one KIR/HLA missing ligand mismatch for the KIR $3 D L 2$ gene; 4) among all available related donors who all have the "best" B KIR gene content, the father is the most suitable donor due to the $10 / 10$ HLA-match between him and his daughter, which is certainly less frequent than the probability of a match between siblings.

\section{ACKNOWLEDGMENTS}

The authors thank the entire team members of the Tissue Typing Compartment of the Institute for Blood Transfusion of Vojvodina for their dedication to the study. The authors are grateful to Vojvodić Vuk (Advanced University Student, Faculty of Economics and Engineering Management, University of Novi Sad, Novi Sad, Novi Sad, Serbia), for his excellent technical assistance and computer design work.

Declaration of Interest. The authors report no conflicts of interest. The authors alone are responsible for the content and writing of this article.

\section{REFERENCES}

1. Rajalingam R. Human diversity of killer cell immunoglobulin-like receptors and disease. Korean J Hematol. 2011; 46(4): 216-228.

2. Jiang W, Johnson C, Jayaraman J, Simecek N, Noble J, Moffatt MF, et al. Copy number variation leads to considerable diversity for B but not A haplotypes of the human KIR genes encoding NK cell receptors. Genome Res. 2012; 22(10): 1845-1854.

3. Hou L, Chen M, Ng J, Hurley CK. Conserved KIR allele-level haplotypes are altered by microvariation in individuals with European ancestry. Genes Immun. 2012; 13(1): 47-58.

4. Gardiner CM, Guethlein LA, Shilling HG, Pando M, Carr WH, Rajalingam R, et al. Different NK cell surface phenotypes defined by the DX9 antibody are due to KIR 3DL1 gene polymorphism. J Immunol. 2001; 166(5): 2992-3001.

5. Trowsdale J, Barten R, Haude A, Stewart CA, Beck S, Wilson MJ. The genomic context of natural killer receptor extended gene families. Immunol Rev. 2001; 181(1): 20-38.

6. Li H, Pascal V, Martin MP, Carrington M, Anderson SK. Genetic control of variegated KIR gene expression: Polymorphisms of the bi-directional KIR3DL1 promoter are associated with distinct frequencies of gene expression. PLoS Genet. 2008; 4(11): e1000254. doi: 10.1371/journal.pgen.1000254.

7. Ludajic K, Balavarca $\mathrm{Y}$, Bickeböller $\mathrm{H}$, Rosenmayr A, Fae I, Fischer GF, et al. KIR genes and KIR ligands affect occurrence of acute GVHD after unrelated, 12/12 HLA matched, hematopoietic stem cell transplantation. Bone Marrow Transplant. 2009; 44(2): 97-103.

8. Pyo C-W, Guethlein LA, Pyo QV, Wang R, AbiRached L, Norman PJ, et al. Different patterns of evolution in the centromeric and telomeric regions of group A and B haplotypes of the human killer cell Ig-like receptor locus. PLoS ONE. 2010; 5(12): e15115. doi: 10.1371/journal. pone. 0015115 .

9. Shilling HG, Guethlein LA, Cheng NW, Gardiner $\mathrm{CM}$, Rodriguez R, Tyan D, et al. Allelic polymorphism synergizes with variable gene content to individualize human KIR genotype. J Immunol. 2002; 168(5): 2307-2315. 
10. Middleton D, Meenagh A, Gourraud PA. KIR haplotype content at the allele level in 77 Northern Irish families. Immunogenetics. 2007; 59(2): 145-158.

11. Garcia CA, Robinson J, Guethlein LA, Parham P, Madrigal JA, Marsh SG. Human KIR sequences 2003. Immunogenetics. 2003; 55(4): 227-239.

12. Wilson MJ, Torkar M, Haude A, Milne S, Jones $\mathrm{T}$, Sheer $\mathrm{D}$, et al. Plasticity in the organization and sequences of human KIR/ILT gene families. Proc Natl Acad Sci USA. 2000; 97(9): 47784783.

13. Hsu KC, Chida S, Dupont B, Geraghty DE. The killer cell immunoglobulin-like receptor (KIR) genomic region: Gene-order, haplotypes and allelic polymorphism. Immunol Rev. 2002; 190: 40-52.

14. Gourraud PA, Meenagh A, Cambon-Thomsen A, Middleton D. Linkage disequilibrium organization of the human KIR superlocus: Implications for KIR data analyses. Immunogenetics. 2010; 62(11-12): 729-740.

15. Becker $\mathrm{S}$, Tonn $\mathrm{T}$, Füssel $\mathrm{T}$, Uhrberg $\mathrm{M}$, Bogdanow M, Seifried E, et al. Assessment of killer cell immunoglobulin-like receptor expression and corresponding HLA class I phenotypes demonstrates heterogenous KIR expression independent of anticipated HLA class I ligands. Hum Immunol. 2003; 64(2): 183-193.

16. Niokou D, Spyropoulou-Vlachou M, Darlamitsou A, Stavropoulos-Giokas C. Distribution of killer cell immunoglobulin-like receptors in the Greek population. Hum Immunol. 2003; 64(12): 11671176.

17. Bontadini A, Testi M, Cuccia MC, Martinetti M, Carcassi C, Chiesa A, et al. Distribution of killer cell immunoglobulin-like receptors genes in the Italian Caucasian population. J Transl Med. 2006; 4(1): 44-53.

18. Gutiérrez-Rodríguez ME, Sandoval-RamHrez L, Díaz-Flores M, Marsh SG, Valladares-Salgado A, Madrigal JA, et al. KIR gene in ethnic and Mestizo populations from Mexico. Hum Immunol. 2006; 67(1-2): 85-93.

19. Pavlova Y, Kolesar L, Striz I, Jabor A, Slavcev A. Distribution of KIR genes in the Czech population. Int J Immunogenet. 2008; 35(1): 57-61.
20. Velickovic M, Velickovic Z, Panigoro R, Dunckley H. Diversity of killer cell immunoglobulin-like receptor genes in Indonesian populations of Java, Kalimantan, Timor and Irian Jaya. Tissue Antigens. 2009; 73(1): 9-16.

21. Augusto DG, Piovezan BZ, Tsuneto LT, Martin MP, Carrington M, Petzl-Erleret ML. Diversity of the KIR gene cluster in an urban Brazilian population. Immunogenetics. 2012; 64(2): 143152.

22. Constantinescu I, Nedelcu FD, Toader MA, Vasile D, Zaharia M, Harza M, et al. Evaluation of KIR genotypes and cytokine gene polymorphism in Romanian kidney transplant recipients: Impact on acute and chronic allograft rejection. Tissue Antigens. 2006; 67(6): 505-506.

23. Djulejić E, Trajkov D, Petlichkovski A, Hristomanova S, Middleton D, Spiroski M. Distribution of killer cell immunoglobulin-like receptors in the Macedonian population. Hum Immunol. 2010; 7(3): 281-288.

24. Kamenarić Burek M, Grubić Z, Stingl K, Žunec R. Distribution of KIR genes in the Croatian population. Hum Immunol. 2013; 74(8): 952956.

25. Single RM, Martin MP, Gao X, Meyer D, Yeager $\mathrm{M}$, Kidd JR, et al. Global diversity and evidence for coevolution of KIR and HLA. Nat Genet. 2007; 39(9): 1114-1119.

26. Lee YC, Chan SH, Ren EC. Asian population frequencies and haplotype distribution of killer cell immu-noglobulin-like receptor (KIR) genes among Chinese, Malay, and Indian in Singapore. Immunogenetics. 2008; 60(11): 645-654.

27. Middleton D, Meenagh A, Moscoso J, ArnaizVillena A. Killer immunoglobulin receptor gene and allele frequencies in Caucasoid, Oriental and Black populations from different continents. Tissue Antigens. 2008; 71(2): 105-113.

28. Wende H, Volz A, Ziegler A. Extensive gene duplications and a large inversion characterize the human leukocyte receptor cluster. Immunogenetics. 2000; 51(8-9): 703-713.

29. Martin MP, Bashirova A, Traherne J, Trowsdale J, Carrington M. Cutting edge: Expansion of the KIR locus by unequal crossing over. J Immunol. 2003; 171(5): 2192-2195. 
30. Cooley S, Weisdorf DJ, Guethlein LA, Klein JP, Wang T, Le CT, et al. Donor selection for natural killer cell receptor genes leads to superior survival after unrelated transplantation for acute myelogenous leukemia. Blood. 2010; 116(4): 2411-2419.

31. Gonzalez-Galarza FF, Christmas S, Middleton D, Jones AR. Allele frequency net: A database and online repository for immune gene frequencies in worldwide populations Nucleic Acids Res. 2011; 39(Database issue): D913-D919.
32. Norman JP, Abi-Rached L, Gendzekhadze K, Hammond JA, Moesta AK, Sharma D, et al. Meiotic recombination generates rich diversity in NK cell receptor genes, alleles, and haplotypes. Genome Res. 2009; 19(5): 757-769.

33. Norman PJ, Abi-Rached L, Gendzekhadze K, Korbel D, Gleimer M, Rowley D, et al. Unusual selection on the KIR3DL1/S1 natural killer cell receptor in Africans. Nat Genet. 2007; 39(9): 1092-1099. 
